\title{
The University of Manchester
}

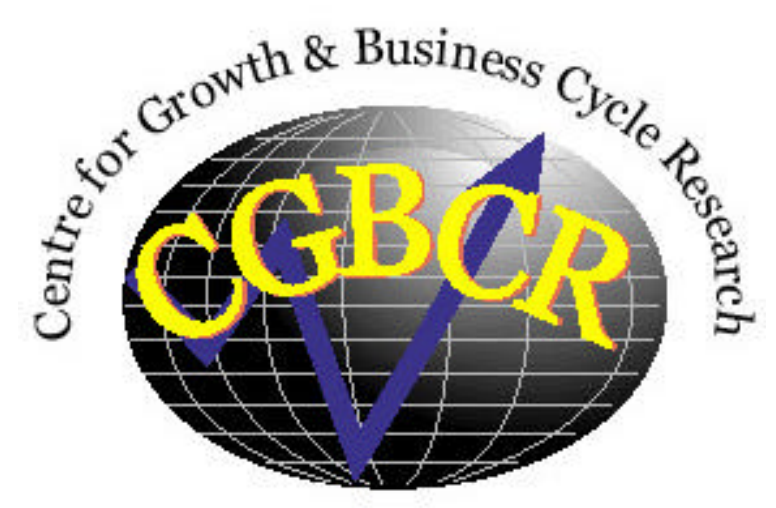

Discussion Paper Series

\section{Financial Development, Financing Choice and Economic Growth}

By

Keith Blackburn, Niloy Bose and Salvatore Capasso

Centre for Growth and Business Cycle Research, School of Economic Studies, University of Manchester, Manchester, M13 9PL, UK

\section{Download paper from:}

http://www.ses.man.ac.uk/cgbcr/discussi.htm

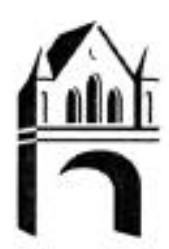




\title{
Financial Development, Financing Choice and Economic Growth
}

\author{
Keith Blackburn, Niloy Bose and Salvatore Capasso \\ Centre for Growth and Business Cycle R esearch \\ School of Economic Studies, University of Manchester
}

J anuary 10, 2001

\begin{abstract}
A bstract
In an overlapping generations economy households (lenders) fund risky investment projects of ..rms (borrowers) by drawing up loan contracts on the basis of asymmetric information. A n optimal contract entails either the issue of only debt or the issue of both debt and equity according to whether a household faces a single or a double moral hazard problem as a result of its own decision about whether or not to undertake costly information acquisition. The equilibrium choice of contract depends on the state of the economy which, in turn, depends on the contracting regime. Based on this analysis, the paper provides a theory of the joint determination of real and ..nancial development with the ability to explain both the endogenous emergence of stock markets and the complementarity between debt ..nance and equity ..nance.
\end{abstract}

\section{Introduction}

Over the past decade, a substantial volume of research has been devoted towards verifying and understanding the existence of linkages between the real and ..nancial development of economies. One such linkage is evidenced by the strong positive (and possibly two-way causal) correlation between long-run economic growth and the degree of ..nancial intermediation (e.g., De Gregorio and Guidotti 1992; King and Levine 1993a,b; Levine and Renelt 1992;

\footnotetext{
${ }^{\circledR}$ The authors are grateful for the ..nancial support of the ESRC (Grant No.R 000222871). The usual disclaimer applies.
} 
Roubini and Sala-i-Martin 1991). A nother is demonstrated by the similar correlation between long-run growth and stock market activity (e.g., Atje and J ovanovic 1993; Demirgüç-K unt and Levine 1996a,b; Levine and Zervos 1995, 1996, 1998). Broadly speaking, both of these relationships may be explained by appealing to the opportunities made available for channelling a larger fraction of savings into investment and for undertaking more productive types of investment as a result of costly improvements in ..nancial arrangements which wealthier economies are better able to axord. In the case of ..nancial intermediation, to which most of the theoretical literature is devoted, these opportunities may arise from a greater pooling of risks, a higher quality of information, a lower cost of monitoring and a lower cost of transactions (e.g., Bencivenga and Smith 1991; Blackburn and Hung 1998; Bose and Cothren 1996, 1997; B oyd and Smith 1992; Cooley and Smith 1998; De La Fuente and Marin 1994; Greenwood and J ovanovic 1990; King and Levine 1993b; Sussman 1993; Sussman and Zeira 1993; Zilibotti 1994). In the case of stock markets, where the body of theory is a little thinner, they may rełect a wider diversi..cation of portfolios and a re-direction of resources towards longer run, less liquid but higher yielding projects (e.g., Bencivenga et al. 1995; Devereux and Smith 1994; Levine 1991; Obstfeld 1994; Saint-Paul 1992). ${ }^{1}$

Each of the above relationships may be viewed as being particularly relevant for a certain class of economies - for example, developing economies (where commercial and central banks are the dominant ..nancial institutions), or more advanced economies (where the market capitalisation of ..rms is much higher). What is notable is that, almost without exception, each relationship has been studied in isolation with no connection to the other. Yet it has been widely recognised for some time that ..nancial development is a multi-faceted process that takes place through various distinct stages - from the emergence and expansion of debt-oriented ..nance to the materialisation of stock markets and the increasing use of equity as an additional instrument by which ..rms are able to raise funds (e.g., Goldsmith 1969; Gurley and Shaw 1955, 1960). Modelling this process has so far eluded the attention of most researchers and there remains little by way of a complete account of events that lead an economy to undergo transition from a ..nancial system based wholly or predominantly on the issue of debt to one involving a much greater (though not exclusive) reliance on the issue of equity.

\footnotetext{
${ }^{1}$ Of course, there are exceptions to the conventional wisdom that ..nancial development is necessarily conducive to real development. In some of the above models, for example, a reduction in uncertainty due to a greater sharing of risks may reduce precautionary savings by far enough to reduce growth as well (e.g., Bencivenga and Smith 1991; Devereux and Smith 1994; Obstfeld 1994).
} 
The only exceptions to the above that we know of are the contributions by Boyd and Smith $(1996,1998)$. These authors develop a dynamic general equilibrium model in which producers of capital choose between two dixerent types of technology that are ..nanced in two dixerent ways. The ..rst type of technology is one that yields a relatively low expected return, is publicly observable and is ..nanced by means of equity at no expense. The second type of technology is one that yields a relatively high expected return, is not directly observable by lenders and is ..nanced by means of debt subject to a standard costly state veri..cation problem (e.g., Diamond 1984; Townsend 1979). ${ }^{2}$ Assuming plausible parameter values, it is shown that there is a critical level of per capita income below which only a debt market exists. As capital accumulation takes place, however, the cost of state veri..cation increases due to $a$ fall in the relative price of capital. Eventually (i.e., once the threshold level of income is reached), a stock market emerges as ...rms begin to make more use of the observable technology and less use of the unobservable technology, implying an increase in the amount of equity ..nance relative to debt ..nance.

The present paper shares the same basic objective as that of B oyd and Smith $(1996,1998)$ - namely, to model the co-evolution of the real and ... nancial sectors of an economy in a way that enables one to explain why the emergence of stock markets occurs relatively late in this process and why debt markets continue to remain active thereafter. Our approach to this is based on an analysis that is quite dixerent, however, from the analysis presented by those authors. We imagine an economy in which households (lenders) fund risky investment projects of ..rms (borrowers) by drawing up loan contracts involving some optimally-determined combination of debt and equity. Capital market imperfections arise due to asymmetric information: each household is unable to observe (and therefore control) directly both the type of project selected by a ..rm and the level of exort that a ..rm devotes to running its project. The ..rst of these diф culties can be resolved if a household is prepared to spend a ..xed amount of resources on choosing a project, itself, and enforcing this choice on a ..rm, in which case the household is confronted by a single moral hazard problem in terms of the ..rm's input of exort. If, on the other hand, a household is not willing to undertake such action, then it is faced with a double moral hazard problem over a ..rm's

\footnotetext{
${ }^{2}$ In the type of framework considered by the authors, the assumption of two technologies (the innovation of their analysis) is crucial. If there was only a single (unobservable) technology, then a stock market would never emerge since the veri..cation costs associated with the use of debt would always be lower than the veri..cation costs associated with the use of equity because debt claims, unlike equity claims, make contractual payments contingent on a ..rm's performance only in the event of bankruptcy.
} 
selection of both its exort and project. We show that the optimal contract that solves the single moral hazard problem is a pure debt contract, whereas the optimal contract that solves the double moral hazard problem is a mixed debt-equity contract. Signi..cantly, the actual (preferred) choice of contract both in uences and is infuenced by the state of the economy such that only debt ..nancing takes place at relatively low levels of development along a relatively low capital accumulation path, while both debt and equity ...nancing occur at relatively high levels of development along a relatively high capital accumulation path. Accordingly, the economy displays multiple development regimes associated with dixerent growth trajectories and dixerent ..nancial systems. Transition between these regimes is characterised by the endogenous emergence of a stock market which has a positive feedback exect on growth. Transition is not inevitable, however, and there exists the possibility of multiple long-run outcomes which depend fundamentally on initial conditions.

The implication of our model that both debt and equity markets are active at same time during the later stages of development may appear to be somewhat at odds with the popular belief that debt and equity represent substitute sources of corporate ..nance. Yet there is strong evidence to suggest that this belief is misguided and that debt and equity act more as complements to each other (e.g., Demirgüç-K unt and Levine 1996a,b; Demirgüç-K unt and Maksimovic 1996). In Boyd and Smith (1996, 1998) this complementarity arises because of an increase in the cost of pure debt ..nancing to such an extent that it eventually becomes infeasible for ..rms to continue issuing debt without also issuing equity. In our analysis complementarity is realised as a natural outcome of lenders' optimal decisions in the face of multiple moral hazard problems. A positive growth exect from the emergence of a stock market in response to these problems is explained by the cost savings to lenders from leaving project investment decisions entirely up to borrowers. This accords with the view that one of the major impediments to real economic development is the loss of resources associated with informational frictions in ..nancial markets (e.g., McK innon 1973; Shaw 1973).

The paper is organised as follows. In Section 2 we present a description of the economic environment. In Section 3 we de..ne and solve the optimal loan contracting problem under dixerent scenarios. In Section 4 we study the optimal choice of contract in dynamic general equilibrium and examine the implications for capital accumulation and growth. In Section 5 we conclude with a discussion of our results. 


\section{The Economy}

Time is discrete and indexed by $t=0 ; 1 ; \ldots ; 1$. There is a countable in..nite number of two-period-lived agents belonging to overlapping generations of non-altruistic families. Each generation is divided at birth into two groups of market participants - households (or workers, or lenders) and ..rms (or entrepreneurs, or borrowers). To ..x ideas, we normalise the total population to 2, assume equal sized groups of mass 1 , and unite newly-born lenders with newly-born borrowers in randomly-matched pairs. ${ }^{3}$ Each household is a ..nancier of a risky capital project when young, a supplier of a ..xed amount of labour when young and a consumer of ..nal output when old. Each ..rm is an operator of a risky project when young, an employer of labour when old and a producer and consumer of ..nal output when old. All agents are risk neutral and all markets are competitive. We proceed with our formal description of the economy with reference to the circumstances facing agents of generation $t$.

Each ..rm begins life with zero resources, except for a unit endowment of time. Each ..rm has an opportunity, however, to undertake a risky investment project from which capital is produced. To exploit such an opportunity, a ..rm must acquire external ..nance from a household (of the same generation). There is a continuum of projects, indexed by $x_{t} 2<_{+}$, each of which gives access to a stochastic technology for converting output and exort at time $t$ into capital at time $t+1$. To be precise, we assume that $I_{t}$ units of loans and $h_{t} 2(0 ; 1)$ units of entrepreneurial time may be combined to produce $\cdot t+1$ units of capital according to

$$
\begin{aligned}
& { }_{\mathrm{t}+1}=\mathrm{A}\left(\mathrm{x}_{\mathrm{t}}\right) \mathrm{I}_{\mathrm{t}}{ }_{\mathrm{t}}^{\circledR} \mathrm{h}_{\mathrm{t}}^{-} ; \quad{ }^{\circledR},{ }^{-} 2(0 ; 1) ;{ }^{\circledR}+^{-}<1 ; \\
& A\left(x_{t}\right)=\begin{array}{l}
x_{t} \text { with probability } p\left(x_{t}\right) ; \\
0 \text { with probability } 1_{i} p\left(x_{t}\right) ;
\end{array}
\end{aligned}
$$

where $p(\Phi 2(0 ; 1)$. Dixerences in the riskiness of projects are captured by

\footnotetext{
${ }^{3}$ The assumption of a one-to-one matching between lenders and borrowers is not uncommon in the literature (e.g., B encivenga and Smith 1993; B ose and Cothren 1996, 1997) and is made in the present context largely to save on notation. As will become apparent, if a lender were to be approached by more than one borrower (each of whom is identical ex ante), then the lender would either divide her loanable funds equally (and on the same terms) between borrowers, or lend only to a single borrower, depending on the nature of the loan contract. Given that there are equal numbers of lenders and borrowers, the equilibrium outcome in each case would be equivalent to a one-to-one matching. Alternatively, the assumption might be justi..ed by appealing to the existence of search costs which prohibit the break-up of any initial lender-borrower pairing. The model is also consistent with the case in which lenders delegate the task of designing and implementing contracts to a manager of a mutual fund.
} 
the assumption that $p q \Phi<0$ so that higher yielding projects have a lower probability of being successful. A convenient speci..cation of this innovation technology is $p\left(\phi=\mathrm{e}^{\mathrm{i}^{1 / x t}}(1 / 2>0)\right.$ which implies an expected level of capital equal to

$$
E\left(\cdot{ }_{t+1}\right)=\left.e^{i^{1 / x t}} x_{t}\right|_{t} ^{\circledR} h_{t}^{-}:
$$

Thus, for given $I_{t}$ and $h_{t}$, there is a unique choice of project, $x_{t}=\frac{1}{1 / 2}$ that maximises expected capital production.

In addition to the above, a young entrepreneur has access to a linear home production technology that enables her to convert her own labour into output. ${ }^{4}$ Productivity in home production is both stochastic and contingent on whether a project is being operated at the same time: with probability $q$, an entrepreneur who runs a project obtains $A\left(1 ; h_{t}\right)$ units of home-produced output, while an entrepreneur who does not run a project receives $\hat{A}_{0}$ units of home-produced output; with probability $1 ; q$, home-produced output is zero whatever the entrepreneur's circumstances. We assume that Á $>A_{0}$ due to positive externalities (spillovers of knowledge) from capital production to home production. This assumption is meant to capture the plausible idea that the operation of a project entails the acquisition of certain transferable skills and expertise that can be used to raise ed ciency in other, more basic, productive activities. ${ }^{5}$ In what follows we de. ne $\odot=\hat{A}_{i} \dot{A}_{0}$ :

The ultimate activity of entrepreneurs is the manufacture of ..nal output in the second period of their lives using a common, non-stochastic technology. The inputs to manufacturing are labour (hired from young households of the next generation) and capital (acquired from risky investments undertaken previously by ..rms of the current generation). A mature entrepreneur employing $n_{t+1}$ units of labour and $k_{t+1}$ units of capital is able to produce $\mathrm{y}_{\mathrm{t}+1}$ units of output according to

$$
\mathrm{y}_{\mathrm{t}+1}=\mathrm{f} \mathrm{n}_{\mathrm{t}+1}^{\mu} \mathrm{k}_{\mathrm{t}+1}^{1_{i}}{ }^{\mu} \mathrm{K}_{\mathrm{t}+1}^{\mu} ; \quad f>0 ; \mu 2(0 ; 1) ;
$$

\footnotetext{
${ }^{4}$ It makes no dixerence to our analysis as to whether one assumes that entrepreneurs consume this output in the ..rst or second period of their lives. We opt for the latter (envisaging either a storage technology or a one period lag in home production) merely for the sake of comparability with the consumption pro..le of households.

${ }^{5} \mathrm{~T}$ his idea has featured in other analyses which emphasise the potential bene..ts from the transference of skills acquired in one task to other occupations (e.g., J ovanovic and Nyarko 1996). Empirically, it has been observed that ..rms are often able to increase the productivity of labour in some of their branches by drawing on various knowledge and expertise gained in others (e.g., B lomstrom et al. 1994). The idea may also be captured by assuming that the operation of a project raises the probability of successful home production.
} 
where $\mathrm{K}_{\mathrm{t}+1}$ denotes the aggregate stock of capital. ${ }^{6}$ Labour is hired at the competitively-determined wage rate $\mathrm{w}_{\mathrm{t}+1}$, while capital is rented at the competitively-determined interest rate $r_{t+1}$. If an entrepreneur produced $\cdot t+1$ units of capital when young, then she is a net borrower of capital if $k_{t+1} i \cdot t+1>0$ and a net lender of capital if $k_{t+1} i \cdot t_{t+1}<0$. Her pro..t is therefore ${ }^{1 / 4+1}=f n_{t+1}^{\mu} k_{t+1}^{1 i} \mu_{t+1}^{\mu} w_{t+1}^{\mu} n_{t+1} i r_{t+1}\left(k_{t+1 i} \cdot t+1\right)$ which, for given values of $w_{t+1}, r_{t+1}, K_{t+1}$ and ${ }_{t+1}$, is maximised by choosing $n_{t+1}$ and $k_{t+1}$ so as to satisfy $\mu f n_{t+1}^{\mu_{i}} k_{t+1}^{1} \mu_{i}^{1} K_{t+1}^{\mu}=w_{t+1}$ and $(1 ; \mu) f n_{t+1}^{\mu} k_{t+1}^{i} K_{t+1}^{\mu}=r_{t+1}$. In equilibrium, where $n_{t+1}=n$ (the ..xed supply of labour) and $k_{t+1}=K_{t+1}$, these conditions become

$$
\begin{gathered}
w_{t+1}=\mu f n^{\mu_{i}}{ }^{1} k_{t+1} ; \\
r_{t+1}=r=\left(\begin{array}{ll}
1 ; & \mu
\end{array}\right) n^{\mu} .
\end{gathered}
$$

Correspondingly, $1 / 4+1=r \cdot t+1$ so that the choice of project which maximises expected capital production (i.e., $x_{t}=\frac{1}{1 / 2}$ is the same as that which maximises expected pro.ts, $E(1 / 4+1)=$ re $\left.^{1 / 2 / x} x_{t}\right|_{t} h_{t}^{-} .7$

Each young household is endowed with one unit of labour, part or all of which is supplied inelastically to old entrepreneurs (producing output) in return for the wage $w_{t}$. Each young household then lends all of her labour income to a young entrepreneur (producing capital) in return for a payment next period. I mperfections in the loan market arise due to asymmetric information between borrowers and lenders. Speci..cally, we assume that a lender is unable to observe (and therefore control) directly both a borrower's choice of project, $x_{t}$, and a borrower's allocation of time to that project, $h_{t}$. The .rst of these dic culties can be resolved if the lender is prepared to devote a ..xed amount of her own time endowment, $1 ;$ ' $2(0 ; 1)$, to acquiring information, choosing a project for herself and enforcing this choice on the borrower. Under such circumstances, the lender has only $n=$ ' units of labour with which to earn income so that the size of her loan is $I_{t}={ }^{\prime} w_{t}$. Alternatively, if the lender does not intervene in project choice, then she loses none of her labour time so that $n=1$ and her loanable fund is $I_{t}=w_{t}$. We also assume that, while the random yield from capital production is publicly observable, the stochastic output of a borrower's home production is private information and cannot, therefore, be used to condition loan repayments. ${ }^{8}$

\footnotetext{
${ }^{6}$ T hus we allow for an aggregate externality in the production of goods, as in many types of endogenous growth model (e.g., Romer (1986)).

${ }^{7} \mathrm{~N}$ ote that the actual production of capital and the actual value of pro..ts will both be zero if a project either fails or commands no entrepeneurial time.

${ }^{8} \mathrm{~T}$ his assumption would be necessary even if a borrower was to consume her home production of output in the ..rst period of life since observation of this output would
} 
The precise functioning of the credit market is as follows. At the be ginning of each period, a newly-born lender is approached by a newly-born borrower with a request for a loan to ..nance a risky investment project. The lender oxers a contract to the borrower, acceptance of which implies a binding agreement that commits the former to a transfer of funds from her current wage earnings and the latter to a repayment of these funds from her future pro..t. As indicated above, only this pro..t (which is publicly observable and which reł ects the realised yield of the project) can be used to set the terms of repayment, there being no other income of the borrower to which the lender can lay any contingent claim. Consequently, a ..rm that fails in its project but continues to produce ..nal output is unable to make any repayment since the pro..t of such a ...rm is driven to zero by competition. ${ }^{9}$

In general, a loan contract between a ..rm and a household allows for both debt and equity ..nance. The terms of such a contract state that, conditional on the success of its project, a ..rm must repay a ..xed amount, $d_{t+1}$, out of its pro..t (its debt payment) plus a share, $\mathrm{s}_{\mathrm{t}+1} 2(0 ; 1)$, of any remaining surplus (its equity payment). Given this, together with the above description of events, we may write the expected lifetime levels of consumption, or utility, of a ..rm and a household engaged in a loan agreement as, respectively,

$$
\begin{aligned}
& E\left(u_{t}\right)=\left(1 ; s_{t+1}\right) e^{i^{1 / x t}}\left(\left.r x_{t}\right|_{t} ^{\otimes} h_{t}^{-} ; d_{t+1}\right)+q A ́\left(1 ; h_{t}\right) ; \\
& E\left(v_{t}\right)=e^{i^{1 / x t}}\left[s_{t+1}\left(r x_{t} t_{t}^{\mathbb{B}} h_{t}^{-} ; d_{t+1}\right)+d_{t+1}\right]:
\end{aligned}
$$

The decision problem for the ..rm is to maximise (6), given the ..nancial contract oxered by the household, while the decision problem for the household is to maximise (7), subject to the behaviour of the ..rm.

\section{Optimal Loan Contracts}

An equilibrium loan contract is a pair of debt and equity claims, $\left(d_{t+1} ; s_{t+1}\right)$, that is feasible to implement and agreeable to both a household and a ..rm. At one extreme, a pure debt contract emerges if the household ..nds it optimal to oxer $\left(d_{t+1} ; 0\right)$ and the ..rm is willing to accept this, in which case the loan repayment is independent of the ..rm's pro..ts. At the other extreme, a pure equity contract transpires if the houshold's preferred oxer is $\left(0 ; \mathrm{s}_{\mathrm{t}+1}\right)$

enable a lender to infer the borrower's exort on a project (which would contradict our other assumption).

${ }^{9} \mathrm{~B}$ ecause of our assumption that the output of a project is publicly observable, a pure debt contract in our model is much simpler than that found in the early debt contracting literature under the opposite assumption (e.g., Diamond 1984; Townsend 1979). 
which the .rm is willing to accept, implying a loan repayment that is wholly conditional on pro..ts. Between these extremes lies the situation in which debt and equity are used optimally together as dixerent means of ..nance.

B efore proceeding to study problems of asymmetric information, it is instructive to consider a frictionless environment where each household is able to costlessly observe and control both the type of project operated by a ..rm and the level of exort that the ..rm devotes to this operation. This serves as a useful benchmark case in which each household achieves its ..rst-best solution by maximising its expected utility in (7) subject only to a ..rm's participation (or individual rationality) constraint which requires that the ..rm's expected payox in (6) is no less than its expected payou from home production in the absence of project investment - that is, $E\left(u_{t}\right), q A_{0}$. The solution is characterised by $x_{t}=\frac{1}{1 / 2}$ and $h_{t}=\left.() r^{-} x_{t}\right|_{t} ^{\circledR} q A^{1 / x t} \frac{1}{1_{i}}=\left.() r^{-}\right|_{t} ^{\circledR} q A^{1} / \mathbb{Q}^{1 i^{-}}$, where $I_{t}=w_{t}, w_{t}=\mu f k_{t}$ (from (4)) and $r=(1 ; \mu) f$ (from (5)). Thus the household selects that project which maximises expected capital production for any given level of exort which, in turn, is selected optimally conditional on this project and the size of the loan. The method of ..nancing is irrelevant in this case.

In fact a household cannot impose its preferred choices on a ..rm without cost. Neither the type of project nor level of exort selected by the ..rm, itself, is directly observable by the household. As such, the household has no immediate control over the ..rm's actions and problems of moral hazard arise, to which an optimal loan contract must provide a solution. As indicated earlier, a household is endowed with the option of eliminating part of its uncertainty by investing $1 \mathrm{i}$ ' units of its own labour time in acquiring information and enforcing the project of its choice. If the household exercises this option, then it is confronted by a single moral hazard problem with respect to the ..rm's input of exort; if not, then it is faced with a double moral hazard problem over the ..rm's selection of both exort and project. These dixerent scenarios have dixerent implications not only for the amount of loanable funds available, but also for the structure of the optimal ..nancial arrangement. We consider each of them in turn.

The decision problem for a household that takes charge of project selection is de..ned as

P 1:

$$
x_{t} ; d_{t+1} ; s_{t+1} \operatorname{maxe}^{1 / 2 / x t}\left[s_{t+1}\left(b x_{t} t_{t}^{B} h_{f ; t}^{-} ; \quad d_{t+1}\right)+d_{t+1}\right] ;
$$

s.t. $h_{f ; t}=h_{t} \arg \max \left(1 ; s_{t+1}\right) e^{i^{1 / x t}}\left(b_{t} p_{t} p_{t}^{-} h_{t}^{-} d_{t+1}\right)+q A ́\left(1 ; h_{t}\right)$;

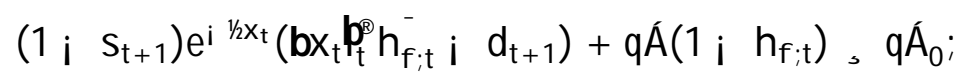

$$
d_{t+1}, 0 ; 0 \cdot s_{t+1} \cdot 1 ;
$$


where $l_{t}={ }^{\prime} t_{t}=\mu f^{\prime} 1_{i} \mu_{k_{t}}$ and $b=(1 ; \mu) f^{\prime} \mu$. The .rst constraint speci..es the ..rm's optimal level of exort, $h_{f ; t}$, given the behaviour of the household, while the second constraint is the ..rm's individual rationality condition. The solution to problem P1, established in the Appendix, is given by the quadruplet $f b_{t} ; a_{t} ; d_{t+1} ; \phi_{t+1} g$ such that

$$
\begin{aligned}
& b_{\mathrm{t}}=\frac{1}{1 / 2} \\
& p_{t}=() b^{-} p_{t}^{B} q A^{1} / Q^{\frac{1}{T_{i}}} ;
\end{aligned}
$$

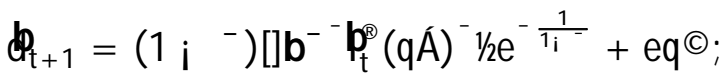

$$
\begin{aligned}
& b_{t+1}=0 \text { : }
\end{aligned}
$$

In this case, therefore, the optimal loan contract is a pure debt contract. The reason is straightforward. Observe that the ..rm's optimising response to the actions of the household is to set its level of exort according to $h_{f ; t}=$ []$\left(1 ; s_{t+1}\right) b^{-} x_{t} b_{t}^{8} q e^{1 / 3 t_{t}} \frac{1}{1_{i}}$. Given this, then the household's best strategy is to implement directly its ..rst-best choice of project (over which it has complete control) and to induce a level of exort as close as possible to its ..rstbest level by setting $\mathrm{s}_{\mathrm{t}+1}$ at its minimum permissable value (i.e., zero). The household's oxer of debt as a single means of ..nance is an optimal solution in the presence of a single moral hazard problem. The ..rm's participation constraint is binding in this case (i.e., $\left.E\left(u_{t}\right)=q A_{0}\right)$ so that the household extracts all of the surplus from the arrangement. ${ }^{10}$

By contrast, the decision problem for a household that does not intervene in the choice of project is de.ned as

$$
\begin{aligned}
& d_{t+1} ; s_{t+1} \operatorname{maxe}^{1 / 2 / x_{f} ;}\left[s_{t+1}\left(e x_{f ; t} t_{t}^{e} h_{f ; t}^{-} ; d_{t+1}\right)+d_{t+1}\right] ; \\
& \text { s.t. } h_{f ; t}=h_{t} \arg \max \left(1 ; s_{t+1}\right) e^{i^{1 / x t}}\left(e x_{t} f_{t}^{e} h_{t}^{-} ; d_{t+1}\right)+q A\left(1 ; h_{t}\right) \text {; }
\end{aligned}
$$

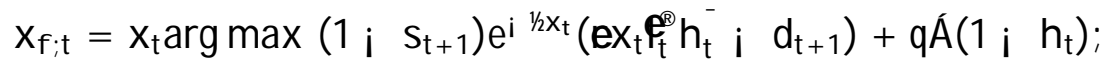

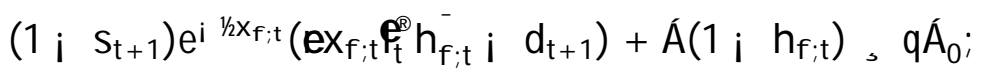

$$
\begin{aligned}
& d_{t+1}, 0 ; 0 \cdot s_{t+1} \cdot 1 \text {; }
\end{aligned}
$$

where $e_{t}=\mathbb{t}_{t}=\mu f k_{t}$ and $e=(1 ; \mu) f$. The set of constraints now includes the ..rm's reaction functions for determining both its input of exort,

\footnotetext{
${ }^{10}$ In principle, the household could implement a contingent claims contract for establishing exactly the same outcomes. It could do this because it is able infer the ..rm's level of exort ex post through its observation of project choice and project outcome. To the extent that it is more costly to enforce a contract through punishments rather than incentives (e.g., because of costly litigation), our non-contingent claims contract would dominate.
} 
$h_{f ; t}$, and its selection of project, $x_{f ; t}$. The solution to problem $\mathrm{P} 2$, also derived in the A ppendix, is given by the quadruplet $f \mathbb{R}_{t} ; \hat{A}_{\mathrm{t}} ; \mathbb{A}_{\mathrm{t}+1} ; \hat{\Theta}_{\mathrm{t}+1} \mathrm{~g}$ such that

$$
\begin{aligned}
& R_{\mathrm{t}}=\frac{1+{ }^{-}}{1 / 2} ; \\
& R_{\mathrm{t}}=[] \mathrm{e}^{-2}\left(1+{ }^{-}\right)^{2} \mathrm{e}_{\mathrm{t}}^{\circledR} \mathrm{q} \mathrm{A}^{1} / \mathrm{e}^{1+-\frac{1}{1_{i}}} ;
\end{aligned}
$$

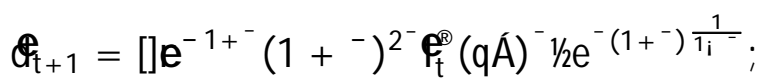

$$
\begin{aligned}
& \mathrm{O}_{\mathrm{t}+1}=1 \mathrm{i}^{-}\left(1+^{-}\right) \text {: }
\end{aligned}
$$

Thus, under the assumption that ${ }^{-}\left(1+{ }^{-}\right)<1$, the optimal loan contract is now a mixed debt-equity contract. The intuition in this case runs as follows.

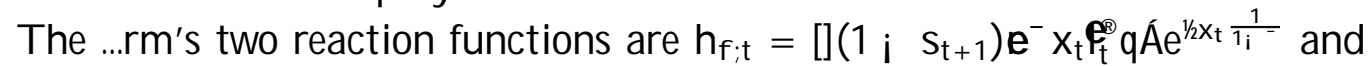
$x_{f ; t}=\frac{1}{1 / 2}+\frac{d_{t+1}}{e_{t}^{e^{8}} h_{t}}$. Suppose that the household was to oxer a pure debt contract so that $d_{t+1}>0$ while $s_{t+1}=0$. The ..rm's optimal response would be to select a type of project and a level of exort that are both dixerent from the household's ..rst-best choices. Conversely, suppose that the household was to oxer a pure equity contract so that $d_{t+1}=0$ while $s_{t+1}>0$. Then the ..rm would deliver the household its ..rst-best choice of project but not its ..rstbest choice of exort. Neither of these contracts is able to yield the complete set of ..rst-best outcomes for the household and each of them turns out to be dominated by a mixed contract. Relative to those ..rst-best outcomes, this contract induces a riskier choice of project and a lower input of exort. The ..rm's participation constraint is non-binding in this case (i.e., $\left.E\left(u_{t}\right)>q \hat{A}_{0}\right)$ so that the..rm is able to retain a share of its pro..ts in excess of its reservation level. A nalagous to the above, the household's oxer of both debt and equity as two means of ..nance is an optimal solution in the presence of two moral hazard problems.

\section{Equilibrium Finance and Capital Accumu- lation}

The foregoing analysis identi..es the optimal loan contract for a given set of circumstances. If a lender decides to take control of project choice, then she will oxer a contract based solely on debt ..nance. If a lender decides not to take control of project choice, then she will oxer a contract based on both debt and equity ..nance. Our immediate next task is to determine which of these arrangements is preferred by a lender, from which we may then proceed to characterise the complete dynamic general equilibrium of the economy. 
A lender's expected utility under each contractual arrangement can be computed straightforwardly by substituting the relevant set of expressions obtained above - either (8)-(11) or (12)-(15) - into (7). Thus

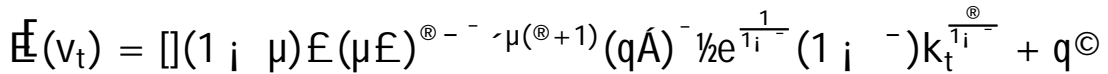

$$
\begin{aligned}
& \bullet \mathrm{k}_{\mathrm{t}}^{\frac{\circledast}{1 i}}+q \odot
\end{aligned}
$$

in the case of a debt-only contract, and

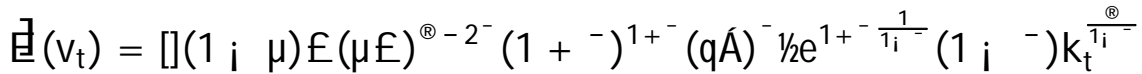

$$
\begin{aligned}
& \vartheta k_{t}^{\frac{\circledast}{1 i}}
\end{aligned}
$$

in the case of a debt-plus-equity contract. Under both arrangements, therefore, the lender's expected utility depends on the level of capital. It is this feature that accounts for the endogeneity of the contracting regime along the economy's path of development. A comparison of (16) and (17) reveals that the lender's preferred choice of contract depends on whether

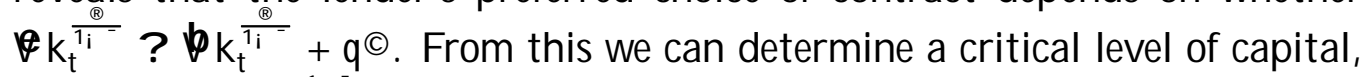
$\mathrm{k}^{\mathrm{c}}=() \mathrm{q} \odot \mathrm{i} \phi \frac{1 \mathrm{i}-}{\oplus}$, below which the preferred choice is a pure debt contract and above which the preferred choice is a mixed debt-equity contract. For our analysis to be non-trivial, we require $\mathrm{k}^{\mathrm{c}}>0$ which entails the parameter restriction $\forall>\downarrow$, or $\frac{-^{-}\left(1+^{-}\right)^{1+^{-}}}{\mathrm{e}}>{ }^{\prime} \mu(\mathbb{B}+1)$. This states that the cost to the lender of implementing a pure debt contract (i.e., the cost of enforcing her own choice of project) cannot be too small. If this cost is negligible, then the lender would always be better ox under such a contract since she would always be closer to her ..rst-best solution and would always be able to extract the entire surplus. Consequently, no stock market would ever emerge. ${ }^{11}$ As it is, the above restriction is necessarily satis..ed by virtue of a similar condition that we impose later - namely, $\frac{{ }^{-}\left(1+^{-}\right)^{1+^{-}}}{\mathrm{e}}>{ }^{\prime} \mu\left({ }^{(}+^{-}\right)$. Given this, then our analysis yields the result that the equilibrium loan contract is $\left(\phi_{t+1} ; a_{t+1}\right)$ if $k_{t}<k^{c}$ but $\left(\theta_{t+1} ; \theta_{+1}\right)$ if $k_{t}, k^{c}$. Accordingly, only a debt market exists at relatively low levels of development, while both debt and equity markets are active at relatively high levels of development. Whether or not the latter outcome actually transpires depends on whether or not the economy reaches the critical stage of evolution corresponding to $\mathrm{k}^{\mathrm{c}}$, a matter to which we now turn.

Our model implies that the process of capital accumulation not only determines, but is also determined by, the equilibrium contract outcome. This

\footnotetext{
${ }^{11}$ The same result is possible in the models of Boyd and Smith $(1996,1998)$, where a stock market fails to materialise under certain parameter values.
} 
follows from the fact that each of the inputs to capital production - the type of project, level of exort and size of loan - is chosen dixerently across the two contracting regimes. Given these choices, it is possible to compute the expected amount of capital produced by each ...rm under each regime by re-

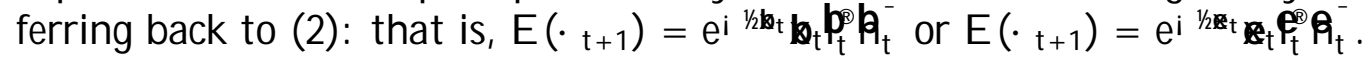
Since there is a countable in..nite number (a unit mass) of ..rms, we may then appeal to the law of large numbers to deduce the following transition paths for the actual stock of capital:

$$
\begin{aligned}
& k_{t+1}=[]((1 ; \mu) f)^{-}(\mu f)^{\circledR-^{-}} \mu\left(\Theta^{-}\right) q^{-} A^{-} 1 / \mathbb{Q}^{\frac{1}{1_{i}}} k_{t}^{\frac{\circledast}{1 i^{-}}} \\
& \text {, } \mathrm{p}_{\mathrm{k}_{\mathrm{t}}^{\frac{\Theta}{1_{i}}}} \text { if } \mathrm{k}_{\mathrm{t}}<\mathrm{k}^{\mathrm{c}} \text {; } \\
& k_{t+1}=[]((1 ; \mu) f)^{-}(\mu f)^{\circledR-2^{-}}\left(1+^{-}\right)^{1+^{-}} q^{-} A^{-} 1 / e^{1+^{-}} \frac{1}{1_{i}} k_{t}^{\frac{\circledast}{1_{i}}} \\
& \text {, } e_{k_{t}}^{\frac{\circledR}{1_{i}}} \text { if } k_{t}, k^{c} \text { : }
\end{aligned}
$$

Under the assumption (alluded to above) that $\frac{{ }^{--}\left(1+^{-}\right)^{1+-}}{e}>{ }^{\prime} \mu\left(\Theta^{-}\right), P>p$ so that the transition path in (19) always lies above the transition path in (18). In this way, we ensure that the existence of a stock market, should it ever emerge, is conducive to real economic development, as suggested by the empirical evidence. ${ }^{12}$ In addition, since ${ }^{\circledR}+^{-}<1$, each of the transition paths is strictly concave and each of them implies convergence to a non-trivial

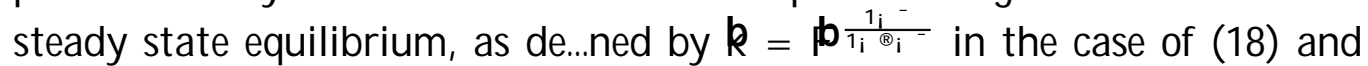
$R=e^{\frac{1 i_{i}}{1_{i} \Theta_{i}}}$ in the case of (19) (where $R<R$ ). These properties are depicted in Figure 1 to which the reader is referred during the following discussion.

Given that $k^{c}<R$ (otherwise the analysis is trivial), one may distinguish between two types of development regime for the economy: the ..rst - a low development regime - is characterised by relatively low levels of economic activity and a ..nancial system in which only the debt market is open; the second - a high development regime - is characterised by relatively high levels of economic activity and a ..nancial system in which both debt and equity markets are open. The overall evolution of the economy depends essentially on the relationship between $\mathrm{k}^{\mathrm{c}}$ and $k$, together with $\mathrm{k}_{0}$ (the initial stock of capital). Suppose that $k_{0}<k^{c}<R$. Under such circumstances, the economy evolves initially along the low growth path (de..ned by (18)) with debt being the only mode of ..nance. On reaching $k^{c}$, the economy jumps

\footnotetext{
${ }^{12}$ For example, among the references cited earlier, Levine and Zervos (1998) report signi..cant positive correlations between various indicators of stock market activity (such as the value of stock trading relative to the size of the loan market, or relative to the size of the economy) and various measures of economic performance (such as current and future rates of capital accumulation, or productivity growth).
} 
to the high growth path (de..ned by (19)) as a stock market materialises to cater for the use of equity as an additional means of ..nance. Thereafter, the economy proceeds along this trajectory and converges to the high steady state equilibrium, $R$. This chain of events describes a process of transition from the low development regime to the high development regime with the endogenous emergence of a stock market. Such an outcome is not inevitable, however. To be sure, suppose that $k_{0}<k<k^{c}$. In this case the economy is destined for the low steady state equilibrium, $k$, being locked forever on the low growth path with only a debt market ever active. To the extent that a stock market would emerge and that the high steady equilibrium would be attained if $\mathrm{k}_{0}>\mathrm{k}^{\mathrm{c}}$, the model now describes a scenario in which limiting outcomes depend fundamentally on initial conditions.

\section{Discussion and Conclusions}

Why do stock markets emerge relatively late in the development process of economies? Why do stock markets emerge at all when there are already other established markets for loans? Why do these other markets continue to operate after stock markets have been formed? And why do economies experience positive growth exects from stock market formation? These are fundamental questions that are posed by a large empirical literature and that are in need of answers from theory. As far as we know, this paper is one of only a few contributions that seek to provide some answers within the context of fully-speci..ed dynamic general equilibrium models.

The linchpin of our analysis is the existence of asymmetric information between borrowers and lenders who must resolve problems of moral hazard through the appropriate design of ..nancial contracts. What is signi..cant about these problems (and the solutions to them) is that they change endogenously with endogenous changes in both the structure of information and the level of economic activity as lenders make optimal decisions about whether or not to spend resources on strengthening their control over borrowers. At low levels of development, it pays lenders to do this and to oxer a single means of ..nance - debt - in response to a single moral hazard problem. At high levels of development, it pays lenders to abstain from such action and to oxer two means of ..nance - debt and equity - in response to two moral hazard problems. Transition from the low to the high development regime is therefore characterised by the endogenous emergence of a stock market which has a positive feedback exect on capital accumulation. Transition is not inevitable, however, and there exists the possibility of multiple long-run outcomes that depend on the intial circumstances of the economy. 
A notable feature of our model as it presently stands is that, if ..nancial transition takes place, it does so abruptly as soon as the critical level of capital, $\mathrm{k}^{\mathrm{c}}$, is reached. This feature has been instilled deliberately in order to focus and simplify the analysis. In principle, the model could be extended to allow for a smoother process of transition and a more gradual adoption of equity ...nance. For example, suppose that entrepreneurs are heterogeneous in their reservation levels of utility, $q \hat{A}_{0}$. Under such circumstances, not all entrepreneurs would begin to issue equity at the same time: only those for

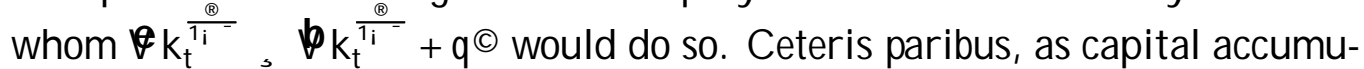
lation proceeds, this condition would become satis..ed for a growing number of ..rms, implying a gradual increase in stock market trading. The analysis of this case is more complicated because of changes in the market wage due to changes in labour supply associated with changes in the distribution of ..rms engaged in dixerent types of contract. Nevertheless, one may surmise that there would be certain parameter con..gurations of the model under which all ..rms end up issuing equity, and certain other parameter con..gurations under which only a subset (including the empty set) of ..rms become part equity ..nanced.

Our analysis is not only successful in stylising the widely-observed positive correlation between real economic development and stock market activity (e.g., Atje and J ovanovic 1993; Demirgüç-K unt and Levine 1996a,b; Levine and Zervos 1995, 1996, 1998), but is also consistent with the long-standing view that one of the major obstacles to growth is the loss of resources due to informational frictions in the capital market (e.g., McK innon 1973; Shaw 1973). This view is also shared by Boyd and Smith $(1996,1998)$ whose analysis, like ours, predicts that these resource costs decline as economies develop and stock markets become more established. In addition, the potential of our model to generate mutliple steady state equilibria means that it is possible to talk of underdevelopment traps in which an economy's real and ..nancial sectors display little co-evolution. A $n$ implication of this case is that an exogenous shock which raises the capital stock above its critical level could have a profound exect on the fortunes of an economy as the ..nancial system is transformed by the rapid materialisation of a stock market. This may be allied to the observation that the deregulation of international capital fows has been associated with surges in stock market activity among many dixerent countries (e.g., Levine and Zervos 1995).

A popular belief is that debt and equity represent substitute sources of corporate ..nance. Recent evidence suggests the opposite that debt and equity act more as complements to each other (e.g., Demirgüç-K unt and Levine 1996a,b; Demirgüç-K unt and Maksimovic 1996). Indeed, an increase in the 
size of the stock market is typically associated with an increase in the volume of debt in many economies. Such evidence has been regarded as a puzzle in demand of an explanation. In Boyd and Smith $(1996,1998)$ the puzzle is resolved on account of an increase in the cost of pure debt ..nance as an economy develops. Eventually, this cost becomes too high for ..rms to feasibly continue their operations by relying on debt ..nance alone and equity emerges as a complementary means of raising funds. In our analysis the cost of pure debt ..nancing also increases with the level of development. At some point, lenders ..nd it optimal to forego incurring this cost and to complement the use of debt with the use of equity as a double-edged strategy for dealing with a double (rather than single) moral hazard problem. 


\section{A ppendix}

In what follows we suppress the indeces on variables to save on notation. In addition, we exploit the fact that the dimensions of each problem can be reduced slightly by ignoring the case in which $s=1$ since this would imply that $\mathrm{h}=0$, meaning that no project would be undertaken.

\section{A. Solution to Problem P 1}

The ..rm's reaction function is

$$
\left.h=[(1 ; s)(q A ́))^{i^{1-}} e^{i^{1 / x t} b x} p^{\circledR}\right]^{\frac{1}{1 i}}:
$$

Given (A 1$)$, it is possible to simplify the problem by converting it to the form

$$
\begin{aligned}
& x ; h ; d m a x e^{i^{1 / x} b x} b^{\circledR} h^{-} \text {i } q A^{-}{ }^{1} h+q A ́\left({ }^{-} b b^{B}\right)^{i}{ }^{1} x^{i}{ }^{1} h^{1_{i}}{ }^{-} d ; \\
& \text { s.t. } q A^{-}{ }^{1}{ }^{1}\left(1 ;{ }^{-}\right) h \text { i } q A^{-}\left(b^{b^{\circledR}}\right){ }^{i}{ }^{1} x^{i}{ }^{1} h^{1_{i}^{-}} d+q \subset, 0 \text {; } \\
& \text { d, } 0 \text {; } \\
& 1 \text { i } q A{ }^{-}\left(b b^{\circledR}\right)^{i}{ }^{1} e^{1 / x} x^{i} h^{1 i}{ }^{-}, 0 \text {; }
\end{aligned}
$$

where $s=1 ; \quad q A ́\left({ }^{-} b^{b}\right)^{i}{ }^{1} e^{1 / x} x^{i}{ }^{1} h^{1_{i}}{ }^{-}$. After various manipulations, the optimality conditions may be written as

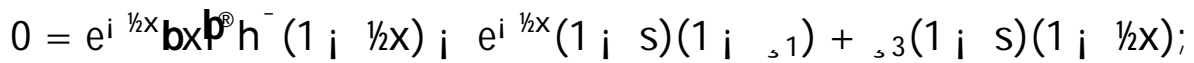

$$
\begin{aligned}
& 0=\mathrm{e}^{\mathrm{i}^{1 / x} \mathrm{bx}} \mathrm{P}^{\otimes} \mathrm{h}^{--} \mathrm{i}\left[1 \mathrm{i},{ }_{1}\left(1 \mathrm{i}^{-}\right)\right] \mathrm{qA} \mathrm{A}^{-} \mathrm{i}^{1} \mathrm{~h} \\
& +\mathrm{e}^{\mathrm{i}^{1 / x}}\left(1 \mathrm{i}^{-}\right)(1 \mathrm{i} \mathrm{s})(1 \mathrm{i}, 1) \mathrm{d} \mathrm{i}, 3\left(1 \mathrm{i}^{-}\right)(1 \mathrm{i} \mathrm{s}) \text {; } \\
& 0=\mathrm{e}^{\mathrm{i} / \mathrm{x}}(1 \mathrm{i} \mathrm{s})(1 \mathrm{i}, 1)+, 2 \text {; }
\end{aligned}
$$

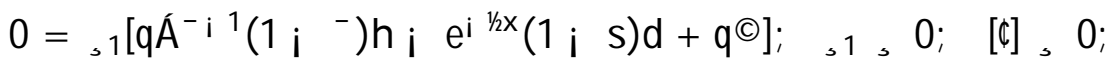

$$
\begin{aligned}
& 0=,{ }_{2} \mathrm{~d} ;, 2,0 ; \mathrm{d}, 0 \text {; } \\
& 0=, 3 \mathrm{~s} ;, 3,0 ; \mathrm{s}, 0 \text {; }
\end{aligned}
$$

where, $\mathrm{i}(\mathrm{i}=1 ; 2 ; 3)$ are the Lagrange multipliers. It is evident from (A 6) that, since $, 2,0,1 \in 0$ so that the ..rm's participation constraint always binds in compliance with (A 7).

$d=0 ; s>0$. From $(A 7)$, it is required that $q A^{-}{ }^{1}{ }^{1}\left(1 i^{-}\right) h+q \subset=0$ which is not possible.

$d>0 ; s>0$. By virtue of $(A 8)$ and $(A 9),, 2=, 3=0$. Thus, $1=1$ from (A 6) and $x=1 / 2^{1}$ from (A 2). Combining (A 3) with (A 1) implies $s=0$ which is a contradiction. 
$d>0 ; s=0$. Since, $2=0$ from (A8), then, $1=1$ from (A 6). Hence $x=1 / 21$ in accordance with (A3). The solution for $h$ is obtained from (A 1$)$,

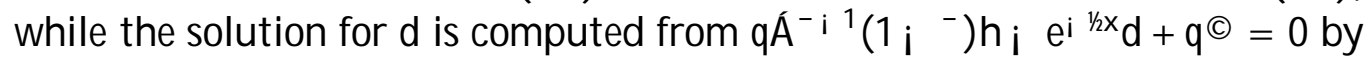
virtue of (A 7). These results are summarised in (8)-(11) of the main text.

\section{B. Solution to Problem P2}

The ..rm's reaction functions are

$$
\begin{aligned}
& h=\left[(1 ; s)(q A)^{i}{ }^{1-} e^{i^{1 / x}} \operatorname{ex} e^{\circledR}\right]^{\frac{1}{i_{i}}} ; \\
& x=1 / 2{ }^{1}+\left(A^{B}\right)^{1} h^{i^{-}} d:
\end{aligned}
$$

As before, (B 1) and (B2) may be used to simplify the problem by transforming it to read

$$
\begin{aligned}
& \mathrm{x} ; \text { hmax } \mathrm{e}^{\mathrm{i}^{1 / x}} \mathrm{ex}^{\mathbb{8} \mathrm{h}^{-}} \mathrm{i}^{1 / 2}{ }^{1} \mathrm{qA}^{-} \mathrm{i}^{1} \mathrm{X}^{\mathrm{i}}{ }^{1} \mathrm{~h} \text {; } \\
& \text { s.t. }\left(1 / 2{ }^{1-i}{ }^{1} x^{i}{ }^{1} ; 1\right) q A ́ h+q \odot, 0 \text {; } \\
& 1 / 2{ }^{1}(1 / x ; 1) \mathbb{E}^{\mathbb{B}} h^{-}, 0 ;
\end{aligned}
$$

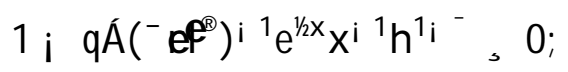

where $d=1 / 2{ }^{1}(1 / x ; 1) e^{\circledR} h^{-}$and $s=1 ; q A\left(^{-} e^{B}\right)^{1} e^{1 / x} x^{i}{ }^{1} h^{1}{ }^{-}$. A ppropriate manipulation yields the following expressions for the optimality conditions:

$$
\begin{aligned}
& \left.0=\mathrm{e}^{\mathrm{i}^{1 / x}} \operatorname{ex}^{\mathrm{B}} \mathrm{h}^{-}\left(1 ;{ }^{1 / x}\right)+{ }^{1 / 2}{ }^{1} \mathrm{e}^{\mathrm{B}} \mathrm{h}^{-} \mathrm{e}^{\mathrm{i}^{1 / x}(1 ;} \mathrm{s}\right)\left(1 ;{ }{ }^{1}{ }_{1}\right) \\
& +{ }_{2}{ }_{2} \operatorname{ex}^{\mathrm{B} h}{ }^{-}+{ }_{3}(1 ; \mathrm{s})\left(1 ;{ }^{1 / x}\right) \text {; }
\end{aligned}
$$

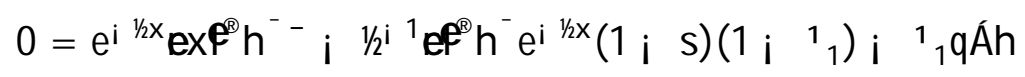

$$
\begin{aligned}
& \mathrm{i}^{1}{ }_{2}^{-1 / 2}{ }^{1}\left(1 ; i^{1 / x}\right) \mathbb{e}^{Q 0} h^{-} i^{1}{ }_{3}\left(1 i^{-}\right)(1 ; s) \text {; } \\
& 0={ }_{1}^{1}\left[\left(1 / 2{ }^{1-} i{ }^{1} X^{i}{ }^{1} ; 1\right) q A ́ h+q \odot\right]=0 ;{ }_{1}, 0 ; \quad[\mathbb{Q}, 0 \text {; } \\
& 0={ }^{1} 2^{1 / 2}{ }^{1}(1 / x ; 1) \mathbb{E}^{\mathbb{B}} h^{-} ;{ }^{1}, 0 ; 1^{1 / 2}{ }^{1}(1 / x ; 1) \mathbb{E}^{\mathbb{8}} h^{-}, 0 \text {; } \\
& 0={ }_{3} \mathrm{~S}{ }^{1}{ }_{3}, 0 \text {; } \mathrm{s}, 0 \text {; }
\end{aligned}
$$

where ${ }^{1}{ }_{i}(i=1 ; 2 ; 3)$ are the Lagrange multipliers.

Case $1 d=0 ; s>0$. From (B6) (recalling that $d=1 / 2^{1}(1 / x ; 1) \mathrm{E}^{\mathrm{e}} \mathrm{h}^{-}$) and (B 7), $1 / x=1$ and ${ }^{1}{ }_{3}=0$.

i) Suppose that ${ }^{1}{ }_{1}=0$. Then (B 3) cannot be satis..ed.

ii) Suppose that ${ }^{1}{ }_{1}>0$. Then (B5) requires that ${ }^{-}{ }^{1}\left(1 i^{-}\right) q A ́ h+q \odot=0$ which is not possible. 
Case $2 d>0 ; s=0$. By virtue of $(B 6),{ }_{2}=0$ and $1 / x>1$. Combining (B3) with (B4) reveals that $1 \mathrm{i}^{1 / x}+^{-}, 0$ must hold.

i) Suppose that ${ }^{1}{ }_{1}>0$. Then (B5) requires that $\left(1 / 1^{1-i}{ }^{1} x^{i}{ }^{1} i 1\right) q A ́ h+q \odot=0$ so that $1 / x^{-}>1$ must hold. This is consistent with $1 i^{1 / x} \times+^{-}>0$ only if ${ }^{-}\left(1+{ }^{-}\right)>1$ which is ruled out by assumption.

ii) Suppose that ${ }^{1}{ }_{1}=0$. If ${ }^{1}{ }_{3} 60$, then (B3) and (B4) imply the quadratic equation $(\mathrm{px})^{2} \mathrm{i} 2(1 / \mathrm{x})+^{-}=0$, to which the only feasible solution is $1 / x=$ $1+\left(1 i^{-}\right)^{\frac{1}{2}}$ which must satisfy $1 i^{1 / x}++^{-}>0$. This is possible only if ${ }^{-}\left(1++^{-}\right)>1$ which is ruled out by assumption. If ${ }_{3}=0$, then (B3) and (B 4) cannot be satis..ed simultaneously.

Case $3 d>0 ; s>0$. From (B6) and (B7), ${ }^{1}{ }_{2}={ }^{1}{ }_{3}=0$ and $1 / x>1$. Combining (B3) with (B 4) reveals that $1 \mathrm{i} 1 / \mathrm{x}+{ }^{-}, 0$ must hold.

i) Suppose that ${ }^{1}>0$. Then (B5) requires that $\left(1_{1}^{1 / 1^{-}} i^{1} X^{i}{ }^{1} i 1\right) q A ́ h+q \odot=0$ so that $1 / x^{-}>1$ must hold. This is consistent with $1 \mathrm{i}^{1 / x} \times+^{-}>0$ only if ${ }^{-}\left(1+^{-}\right)>1$ which is ruled out by assumption.

ii) Suppose that ${ }^{1}{ }_{1}=0$. Then (B3) and (B4) imply $x=1 / 2{ }^{1}\left(1+{ }^{-}\right)$and $s=1_{i}{ }^{-}\left(1+^{-}\right)$. The solution for $h$ is obtained from (B 1$)$, while the solution for $d$ is computed from (B2). These results are summarised in (12)-(15) of the main text. 


\section{R eferences}

[1] Atje, R. and B. J ovanovic, 1993a. Finance and development. Mimeo, New York University

[2] Atje, R. and B. J ovanovic, 1993. Stock markets and development. European Economic Review, 37, 632-640.

[3] Bencivenga, V.R. and B.D. Smith, 1991. Financial intermediation and endogenous growth. Review of Economic Studies, 58, 195-209.

[4] Bencivenga, V.R., B.D. Smith and R.M. Starr, 1995. Transactions costs, technological choice and endogenous growth. J ournal of Economic Theory, 67, 153-177.

[5] Blackburn, K. and V.T.Y Hung, 1998. A theory of growth, ..nancial development and trade. E conomica, 65, 107-124.

[6] Blomstrom, M., A. Kokko and M. Zejan, 1994. Host country competition, labour skills and technology transfer by multinationals. W eltwirtschaftliches Archiv, 130, 521-533.

[7] Bose, N. and R. Cothren, 1996. Equilibrium loan contracts and endogenous growth in the presence of asymmetric information. J ournal of $M$ onetary E conomics, 38, 363-376.

[8] Bose, N. and R. Cothren, 1997. A symmetric information and loan contracts in a neo-classical growth model. J ournal of Money, Credit and B anking, 29, 423-439.

[9] Boyd, J.H. and B.D. Smith, 1992. Intermediation and the equilibrium allocation of investment. J ournal of Monetary E conomics, 30, 409-432.

[10] Boyd, J.H. and B.D. Smith, 1996. The co-evolution of real and ..nancial sectors in the growth process. World Bank Economic Review, 10, 371396.

[11] Boyd, J.H. and B.D. Smith, 1998. The evolution of debt and equity markets in economic development. Economic Theory, 12, 519-560.

[12] Cooley, T.F. and B.D. Smith, 1998. Financial markets, specialisation and learning-by-doing. Research in E conomics, 52, 333-361.

[13] De Gregorio, J. and P.E. Guidotti, 1995. Financial development and economic growth. W orld Development, 23, 433-448. 
[14] De La Fuente, A. and J.M. Marin, 1994. Innovation, bank monitoring and endogenous ..nancial development. Universitat Pompeu Fabra Working Paper No.59.

[15] Devereux, M.B. and G.W. Smith, 1994. International risk sharing and economic growth. International Economic Review, 35, 535-550.

[16] Demirgüç-K unt, A . and R. Levine, 1996a. Stock market development and ..nancial intermediaries: stylised facts. World Bank Economic Review, 10, 291-321.

[17] Demirgüç-K unt, A . and R. Levine, 1996b. Stock markets, corporate ... nance and economic growth: an overview. World Bank Economic Review, 10, 223-239.

[18] Demirgüç-K unt, A. and V. Maksimovic, 1996. Stock market development and ..nancing choices of ..rms. W orld Bank E conomic Review, 10, 341-369.

[19] Diamond, D.W., 1984. Financial intermediation as delegated monitoring. Review of Economic Studies, 51, 393-414.

[20] Gale, D. and M. Hellwig, 1985. Incentive compatible debt contracts: the one period problem. Review of Economic Studies, 52, 647-663.

[21] Goldsmith, R.Y., 1969. Financial Structure and Development. New Haven: Yale University Press.

[22] Greenwood, J. and B. J ovanovic, 1990. Financial development, growth and the distribution of income. J ournal of Political Economy, 98, 10761107.

[23] Gurley, H.G. and E.S. Shaw, 1955. Financial aspects of economic development. American E conomic Review, 45, 515-538.

[24] Gurley, H.G and E.S. Shaw, 1960. M oney in a Theory of Finance. Washington, D.C.: B rookings Institution.

[25] J ovanovic, B. and Y. Nyarko, 1996. Stepping stone mobility. NBER Working Paper No.5651.

[26] King, R.G. and R. Levine, 1993a. Finance and growth: Schumpeter might be right. Quarterly J ournal of Economics, 108, 717-737. 
[27] King, R.G. and R. Levine, 1993b. Finance, entrepreneurship and growth. J ournal of Monetary E conomics, 32, 513-542.

[28] Levine, R., 1991. Stock markets, growth and tax policy. J ournal of Finance, 46, 1445-1465.

[29] Levine, R. and D. Renelt, 1992. A sensitivity analysis of cross-country growth regressions. American E conomic Review, 82, 942-963.

[30] Levine, R. and S. Zervos, 1995. Capital control liberalisation and stock market development. Mimeo, World Bank Policy Research Department.

[31] Levine, R. and S. Zervos, 1996. Stock market development and long-run growth. World Bank E conomic Review, 10, 323-339.

[32] Levine, R. and S. Zervos, 1998. Stock markets, banks and economic growth. American Economic Review, 88, 537-557..

[33] McKinnon, R.I., 1973. Money and Capital in Economic Development. Washington, D.C.: B rookings Institution.

[34] Obstfeld, M., 1994. Risk taking, global diversi..cation and growth. American Economic Review, 84, 1310-1329

[35] Roubini, N. and X. Sala-i-Martin, 1991. Financial development, the trade regime and economic growth. NBER Working Paper No.3876.

[36] Saint-Paul, G., 1992. Technological choice, ..nancial markets and economic development. European Economic Review, 36, 763-781.

[37] Shaw, E.S., 1973. Financial Deepening in E conomic Development. New York: Oxford University Press.

[38] Sussman, O., 1993. A theory of ..nancial development. In A. Giovaninni (ed.), Finance and Development: I ssues and Experience. Cambridge: Cambridge University P ress.

[39] Sussman, O. and J . Zeira, 1993. Banking and development. Mimeo, Hebrew University of J erusalem.

[40] Townsend, R., 1979. Optimal contracts and competitive markets with costly state veri..cation. J ournal of E conomic Theory, 21, 265-293.

[41] Williamson, S.D., 1986. Costly monitoring, ..nancial intermediation and equilibrium credit rationing. J ournal of Monetary E conomics, 18, 159179. 
[42] Zilibotti, F., 1994. Endogenous growth and intermediation in an archipelago economy. Economic J ournal, 104, 462-473. 